Didáctica Geográfica n ${ }^{\circ}$ 21, 2020,pp. 147-174

DOI: https://doi.org/10.21138/DG.552

ISSN electrónico: 2174-6451

\title{
REPRESENTACIONES ESCOLARES DEL CLIMA EN EL PAISAJE FLUVIAL DEL RÍO CLARIANO
}

\author{
SCHOOL CLIMATE REPRESENTATIONS IN THE RIVER LANDSCAPE OF THE \\ Clarian river
}

REPRÉSENTATIONS SCOLAIRES DU CLIMAT DANS LE PAYSAGE FLUVIAL DE la rivière Clariano

Benito Campo País

Universidad de Valencia.

Benito.Campo@uv.es

Diego García Monteagudo

Universidad de Valencia.

Diego.Garcia-Monteagudo@uv.es

Recibido: 08/06/2020

Aceptado 09/09/2020

\section{RESUMEN:}

El conocimiento de la relación entre el clima y el paisaje convive con las dificultades propias del ámbito escolar. Para saber qué ocurre en su enseñanza, se analiza por medio del instrumento Evocation 2005 y los registros pictóricos, las representaciones sociales que tiene una parte del alumnado de $1^{\circ}$ ESO. El estudio de caso sobre un paisaje fluvial en un ámbito local confirma la idealización del paisaje y la escasa presencia del clima en las representaciones del alumnado, esto junto con las dificultades de los docentes en su conocimiento disciplinar y su práctica nos conmina 
a quebrar las tradiciones y rutinas escolares para afrontar mejor las explicaciones de las transformaciones ambientales.

\title{
Palabras clave:
}

Didáctica; clima; paisaje; representaciones sociales.

\begin{abstract}
:
Knowledge of the relationship between climate and landscape coexists with the difficulties inherent in the school environment. To find out what happens in their teaching, the social representations of a 1st ESO student are analyzed using the Evocation 2005 instrument and the pictorial records. The case study on a river landscape at a local level confirms the idealization of the landscape and the low presence of the climate in the representations of the students, this together with the difficulties of the teachers in their disciplinary knowledge and their practice, urges us to break the traditions and school routines to better face the explanations of the environmental transformations.
\end{abstract}

\section{KEYWORDS:}

Didactics; climate; landscape; social representations

\section{RÉSUMÉ:}

La connaissance de la relation entre climat et paysage coexiste avec les difficultés du milieu scolaire. Afin de savoir ce qui se passe dans leur enseignement, les représentations sociales d'une partie des étudiants de 1er de l'ESO sont analysées à l'aide de l'instrument Evocation 2005 et des fiches picturales. L'étude de cas sur un paysage fluvial dans un cadre local confirme l'idéalisation du paysage et la faible présence du climat dans les représentations des élèves, ceci ainsi que les difficultés des enseignants dans leurs connaissances disciplinaires et leur pratique nous obligent à rompre les traditions et les routines scolaires pour mieux gérer les explications des transformations environnementales.

\section{MoTS-CLÉS:}

Didactique; climat; paysage; représentations sociales. 
"Los ríos, por último, no son solo ríos. Son paisajes."

(Martínez de Pisón, 2016, p. 258)

\section{INTRODUCCIÓN}

La enseñanza del clima y el paisaje presenta dificultades específicas envueltas en otras generales que se ciernen sobre la educación geográfica escolar. Estas dificultades, que influyen en la construcción del conocimiento disciplinar, se pueden observar a partir de las concepciones que tienen el alumnado y el profesorado. Analizar sus representaciones sociales es una vía para entender los obstáculos al aprendizaje de las transformaciones ambientales por parte del alumnado y la innovación de modelos didácticos del profesorado ${ }^{1}$. Para explicar algunos de los obstáculos con los que se enfrenta el conocimiento geográfico vamos a seguir la metáfora de las muñecas rusas, ya que una contiene a la siguientes. Se centra la cuestión estudiando un caso sobre las representaciones que tiene un alumnado y las dinámicas docentes que se desarrollan para explicar el clima y su relación con el paisaje fluvial del río Clariano.

En primer lugar, como dice Pagès (2000), citando a Develay (1997) y Porlan (1998), el origen de las didácticas específicas proviene de la preocupación por el problema del fracaso escolar y la búsqueda de sus soluciones. En relación con la didáctica de la geografía se ha podido constatar como las tradiciones escolares ejercen un peso influyente en el fracaso escolar de las Ciencias Sociales y en concreto en la enseñanza de la geografía escolar; un estudio realizado en base a las representaciones sociales, refleja cómo influyen de manera predominante estas tradiciones en las decisiones de los docentes, la legislación de los contenidos o la estructura de la asignatura (Campo, GarcíaMonteagudo y Souto, 2019). Las didácticas específicas se desarrollan a partir de las preguntas que se hacen los docentes sobre la práctica y sus problemas, cómo se enseña y se aprenden los contenidos en cada área de conocimiento, como podemos reconocer, por ejemplo, en los trabajos que explican las dificultades y posibles alternativas del estudio del espacio geográfico desde los hechos sociales (Souto, 2013) enseñar el paisaje (García de la Vega, 2011) o el clima (Marrón Gaite, 2011).

En segundo lugar, si nos centramos aún más en el caso específico de la enseñanza del clima y el paisaje, a estos obstáculos generales que suponen las rutinas y las tradiciones escolares hay que añadir algunos elementos concretos que particularizan el problema.

${ }^{1}$ Este trabajo forma parte del proyecto de investigación "Las representaciones sociales de los contenidos escolares en el desarrollo de las competencias docentes" (PGC2018-094491B-C32), financiado por el Ministerio de Ciencia, Innovación y Universidades y cofinanciado con fondos FEDER de la UE.. 
Respecto a los contenidos del tiempo y clima algunos análisis vienen constatando las dificultades para su aprendizaje en los libros de texto o en el curriculum. Por una parte, destacar la complejidad que supone la comprensión de los contenidos y los procedimientos (Tonda y Sebastiá, 2003), a lo que hay que añadir una distribución de los contenidos en el curriculum escolar que no se ajusta a los niveles cognitivos del alumnado (Martínez y Olcina, 2019). Por otra parte, los análisis que realizan Martinez y López (2016) sobre el tiempo y el clima en los manuales escolares de la Educación Primaria, revelan la falta de criterios para enseñar los elementos y factores del clima, una clasificación desigual de los climas de España, la inexistencia de mapas meteorológicos o que no aparezcan todos los elementos propios en las leyendas como escalas numéricas o gráficas. En cuanto a los libros de texto de la ESO (Educación Secundaria Obligatoria) constatar las alteraciones que aparecen, como en las explicaciones de los elementos del medio físico, al anteponer el agua a los tiempos y climas (Olcina, 2017, p. 123).

En tercer lugar, a escala local, un estudio de Martínez y Campo (2017, p. 144) realizado con una muestra significativa de toda la población escolar y universitaria de Ontinyent (Valencia), concluye corroborando la complejidad de aprender estos conceptos de clima y paisaje. La idealización del paisaje, la confusión sobre el efecto invernadero o el cambio climático, no diferenciar entre clima y tiempo atmosférico o la poca alfabetización geográfica en las explicaciones, son una muestra de cómo los hechos expuestos anteriormente, junto con la intervención de los medios de comunicación, han conformado un aprendizaje confuso sobre el clima y el paisaje. Las ideas erróneas, los estereotipos y el conocimiento incompleto sobre la relación clima-paisaje en todas las etapas-niveles educativos desde infantil hasta la universidad, reflejan la vigencia de un conocimiento vulgar, no científico, que se mantiene anclado, persistente, y en el que ha intervenido la educación escolar.

En estos tiempos de transformaciones ambientales por la evolución del clima, cambio climático, hay que interpelar a la investigación didáctica sobre el estudio de la relación del clima y paisaje. Por lo que parece oportuno un estudio que tenga como base el conocimiento de las representaciones sociales de los estudiantes y los docentes, estudios para obtener diagnósticos y construir la innovación didáctica que beneficien la mejora educativa.

\section{EL CLIMA Y EL PAISAJE: LOS PLANTEAMIENTOS Y FUNDAMENTOS PARA LA INVESTIGACIÓN DIDÁCTICA}

El aprendizaje sobre el clima y el paisaje no solo se produce en las aulas, hay un aprendizaje social, por transmisión social y un aprendizaje escolar que transmite el docente. A menudo escuchamos expresiones referentes al cambio del clima, frases como 
"de pequeños teníamos mucho frío en invierno", "ahora no llueve casi", "no hay quien se aclare con este tiempo", aunque como dicen Olcina y Martín (1999, p. 25):

Si recuerda inviernos muy duros en su infancia, quizás los padeció así en su propia piel, al usar vestimentas menos efectivas contra las bajas temperaturas -incluido el uso de pantalón corto- que las actuales o al no disponer de calefacción o agua caliente.

A veces, al evocar episodios o fenómenos meteorológicos, la memoria está limitada y las representaciones adquiridas son diferentes a los hechos y datos acontecidos. Las opiniones testimoniales de los individuos se convierten en razones para el historial meteorológico de un lugar, aunque al contrastar estas impresiones y percepciones personales con datos oficiales las discrepancias son evidentes.

Veamos un ejemplo a escala local. Las últimas inundaciones debidas a la "DANA" en septiembre de 2019 han producido el desbordamiento del río Clariano a la altura de la población de Ontinyent (Valencia). Algunos habitantes de la localidad afirman que la catástrofe es culpa del cambio climático y que el nivel del agua nunca había sido tan elevado. Sin embargo, los datos pluviométricos, ratifican el mismo tipo de inundaciones en el barrio de Canterería de dicha localidad, en los años 1968, 1982, 1992 o 2016, como así lo recoge Guerra (2018, p. 37) en "Clima y tiempo en Ontinyent". Comprobamos pues que las personas tienen un recuerdo vago y desfigurado de las transformaciones que se producen en el medio, bien sea natural o urbano. Pues además de un régimen de lluvias torrenciales intensas y en períodos cortos de tiempo, lo que ocurre es que este río reclama su espacio vital ante una normativa municipal que favorece un urbanismo insostenible. Si bien los fenómenos extremos parece que van siendo en estos últimos años más comunes, no es menos cierto que el barrio afectado está en el llano de inundación de dicho río, además de ser un barrio de población deprimida, pobre.

Estos ejemplos que se producen en la percepción de los fenómenos, hechos, climáticos, provienen y persisten como ideas erróneas, lo que viene investigando la didáctica de la geografía durante el proceso de aprendizaje del clima y paisaje, para distinguir y subsanar el conocimiento vulgar desde el conocimiento escolar académicamente construido.

\subsection{Las representaciones sociales: las ideas de los estudiantes y del profesorado en un estudio con base en la didáctica}

La teoría de las Representaciones Sociales desarrolla la teoría del "habitus" del sociólogo Pierre Bourdieu en la que se incluye la característica psicológica. Lo que sostienen los autores que trabajan en el ámbito de las Representaciones Sociales 
(Moscovici, Jodelet, Abric) es que esa determinación psicológica no es consecuencia de un estímulo interior o de sus neuronas, sino que es una consecuencia cultural derivada de la influencia del medio cultural en que se mueven los individuos, y así se explica la persona. Para desarrollar este tema de las representaciones sociales en el aprendizaje del alumnado nos basamos en los planteamientos teóricos de Bourdieu y de Domingos (2000). Para entender las representaciones sociales en el aprendizaje de la geografía escolar y en la línea de conocer la intencionalidad de los hechos humanos relacionada con el cambio de comportamiento, Souto y García (2019) nos ofrecen una explicación desde la geografía de la percepción y del comportamiento y las representaciones sociales. De esta forma nos situamos en la senda de ver cuál es la incidencia del conocimiento escolar en el comportamiento social.

En diferentes trabajos realizados sobre qué entienden los estudiantes de la Educación Infantil, Primaria, ESO o de Grado universitario sobre el paisaje o el cambio climático aparecen resultados que ponen de manifiesto los estereotipos e idealización que tienen sobre esos conceptos (Arto Blanco, 2010; Barraza, 2000; García-Monteagudo, 2019; Morote, Campo y Colomer, 2019). Pero, ¿qué está ocurriendo para que se den estas explicaciones erróneas y estereotipadas?

Es necesario tener en cuenta que, al estar tratando problemas educativos desde la práctica escolar, el profesorado también tiene un papel protagonista. El docente establece su modelo de enseñanza desde la formación que tiene, las dificultades de la praxis y las decisiones que le permiten realizar esa práctica acorde a unos valores educativos que sean coherentes con su ética. Este compendio se concreta en la enseñanza y se funde con los contenidos que desarrolla en su aula, su plataforma de pensamiento y los objetivos que tiene como docente. El profesorado enseña desde un modelo (García Pérez, 2000) que traslada a sus enseñanzas y que intervienen en el aprendizaje del clima y el paisaje que repercute en el aprendizaje del alumnado.

\subsection{El paisaje y su didáctica: de la percepción a la representación social}

El paisaje es un concepto polisémico y de uso diverso que ha contado con un fuerte desarrollo científico en la geografía, aunque no solo ha sido objeto de estudio de esta disciplina (Nogué, 1985). La aproximación didáctica del paisaje al alumnado de Ontinyent sigue las estrategias de observación, identificación e interpretación (Liceras, 2003) desde presupuestos socioconstructivistas (Vigotsky, 2010). Sobre este asunto interesa saber cómo el alumnado explica el paisaje local, pues otras investigaciones han resaltado la valoración subjetiva de este concepto entre los estudiantes (Cavalcanti, 2010; García de la Vega, 2014). La valoración es un estadio de la percepción o proceso fisiológico que ha sido utilizado en estudios de la geografía de la percepción y del comportamiento 
(Capel, 1973). El comportamiento deriva de esa percepción, que realmente recoge aspectos subjetivos que son compartidos por grupos sociales. Por ello la teoría de las representaciones sociales permite abordar la didáctica del espacio geográfico desde la subjetividad, ya que el comportamiento que se proyecta en un escenario concreto es resultado de esa cosmovisión general (Sammut et al. 2015). Con esta base retomamos la adaptación que Souto (2018) realiza de la trialéctica espacial de Soja (2008) a la comprensión del espacio subjetivo. La percepción criba la información que los sujetos reciben de un modo similar a como las neuronas "espejo" permiten entender la mente de las personas, comprender sus intenciones o desarrollar la empatía (Álvarez, 2013). Así se explica que esta tipología actúe como un filtro que refleja las emociones de los sujetos en la comprensión de la realidad, lo que permite graduar el aprendizaje del paisaje a partir del espacio percibido. De hecho, el espacio percibido es muy semejante al concepto "themata", que filtra las representaciones sociales a partir del discurso de otros agentes (Moscovici, 2015).

Con la perspectiva de las representaciones sociales se cuestionan las propuestas del paisaje político que penetran desde la administración en el ámbito educativo. Esto es posible por la distinción entre paisaje vernacular y paisaje político (Gómez, 2013). La ratificación del Convenio Europeo del Paisaje en España en 2007, no ha tenido suficiente eco en los marcos curriculares de Educación Secundaria, pese a que el enfoque integrador del paisaje podría suponer una comprensión holística e interdisciplinar de este concepto, al mismo tiempo que potenciase estrategias de respeto y cuidado del medio ambiente. En la práctica, la falta de ese enfoque integrador provoca que el alumnado de Educación Secundaria evoque las características naturales de los paisajes en zonas próximas a sus localidades de residencia (Casas, Erneta y Puig, 2018). Esto es relevante por cuanto se ha demostrado que la población escolar suele mencionar actuaciones limitadas en beneficio del medio ambiente (Jaén y Barbudo, 2010) y su percepción se aleja de los problemas reales (Vázquez y Aguaded, 2001).

La acción antrópica suele expresarse de forma minoritaria pese a que desde la Institución Libre de Enseñanza (ILE) se defendió que el ser humano es parte integrante de la naturaleza (Ortega, 2000). Los cambios curriculares sobre los contenidos del paisaje han sido analizados minuciosamente por Casas, Puig y Erneta (2017). Esos autores han identificado que la LOMCE permite la enseñanza del paisaje en la asignatura de Educación Plástica y Visual, un aspecto que se ha tenido en cuenta en la elaboración de la unidad didáctica que ha trabajado el alumnado de esta investigación (Campo, Castellà, Martínez y García-Monteagudo, 2019), ya que este concepto tiene un origen pictórico y estético (Maderuelo, 1996). Con estos presupuestos se han elaborado propuestas didácticas sobre didáctica del paisaje y arte (Fernández, 2016; García-Morís, 2015) que siguen las orientaciones curriculares que posibilitan su tratamiento didáctico como 
modelado del paisaje holístico y como paisaje humanizado resultante de la actividad económica (Casas, Puig y Erneta, 2017). Esa comprensión es posible analizarla desde las representaciones sociales a partir de los rasgos metodológicos que se sintetizan en el siguiente apartado.

\section{LA RELACIÓN CLIMA-PAISAJE: METODOLOGÍA DEL ESTUDIO}

El problema es cómo se produce esa construcción del conocimiento cotidiano sobre un objeto científico, sobre dos conceptos como son el clima y el paisaje. Este estudio como parte de una investigación ${ }^{2}$ mayor contempla el objetivo de descubrir los estereotipos y errores conceptuales en la representación de la relación clima-paisaje. Lo hacemos con una población de $1^{\circ}$ de ESO ya que los participantes del estudio responderán según los conocimientos y la representación mental construida en Educación Primaria.

En una explicación para un estudiante de Educación Primaria cabría decirle que, aparte de otra explicación más sustanciada, el paisaje es lo que observamos en la superficie de la tierra y en la atmósfera. Al fin y al cabo, cuando definimos el paisaje indicamos que se compone por el clima, relieve, vegetación, fauna y acción humana. Sin embargo, nuestra conjetura inicial es que la mayoría del alumnado que termina la Educación Primaria e inicia $1^{\circ}$ de ESO no representa el paisaje en tres dimensiones por lo que no consideran la atmósfera o elementos climáticos que intervienen en el paisaje.

\subsection{Estudio de caso}

La investigación es un estudio de caso (Stake, 1999) realizado durante el curso escolar 2018-19 de Ontinyent (Valencia) con 105 alumnos/as, 53 chicos y 52 chicas, de $1^{\circ}$ de ESO en dos centros escolares, Centro A (público) y Centro B (concertado), Su nivel socieconómico es similiar, nivel medio, pero con alumnado inmigrante de nivel medio-bajo; también han participado 14 docentes de la misma localidad, 7 profesoras y 7 profesores que pertenecen a cinco centros educativos distintos de la formación básica. Este profesorado ejerce su labor en centros públicos (6), concertados (7) o en un público de gestión privada (1). Pertenecen a distintos niveles educativos y enseñan materias como Ciencias Sociales (2), Biología (4), Física y Química (2), Matemáticas (1), Lengua y Literatura (1), Integración Social (1), Administración (1) e Infantil (1). La formación que tienen es coherente con las asignaturas que imparten. Respecto a la edad,

2 Nos referimos a la investigación de tesis doctoral que lleva por título: el conocimiento del clima y paisaje: del diagnóstico a una propuesta de enseñanza, perteneciente al programa de doctorado de investigación en Didácticas Específicas de la Universitat de Valencia en la línea de investigación de Didáctica de la Geografía. 
se encuentran en los siguientes rangos, de más de 56 años hay 3 docentes, entre 46 y 55 años hay 2 docentes, 6 docentes entre 36 y 45 años y 3 docentes entre 25 y 35 años.

Objetivo 1- Verificar cómo explican el clima en el paisaje, cómo entienden la relación clima-paisaje, saber si entre sus ideas centrales se representa el clima como modelador o artífice del paisaje, si el clima aparece de forma residual o si no aparece en absoluto. Para analizar estas premisas tenemos que conocer los conceptos principales que considera al representar un paisaje fluvial concreto.

Objetivo 2- Entender las ideas de las dinámicas docentes en las explicaciones del clima y paisaje. Identificar representaciones sociales vinculadas al profesorado en ejercicio, analizar sus concepciones y conocimiento pedagógico de contenido disciplinar, sobre metodologías y enfoques centrados, en este caso del clima.

Los instrumentos de recogida de información han sido las producciones del alumnado en sus tareas de clase y una entrevista semiestructurada para los docentes.

En cuanto a las producciones del alumnado son extraidas del mismo material didáctico. El alumnado de los centros de secundaria del estudio, Centro A y Centro B, trabajan la misma unidad didáctica y conoce su elaboración ex profeso con carácter experimental y de investigación (Campo, Castellà, Martínez y García-Monteagudo, 2019, p. 8-9). La actividad de clase, objeto de estudio se realiza entre 20 y 30 minutos máximo y se enmarca dentro del conocimiento de las ideas previas del alumnado, por lo que no han tenido referencias anteriores al tema del paisaje, aunque es un paisaje conocido. A las respuestas del alumnado en las tareas, se aplican las técnicas de investigación para analizar las representaciones pictóricas y su interpretación mediante las palabras clave que el alumnado atribuye a un paisaje delimitado, el paisaje comprendido entre el Pou Clar y el Pont Nou de Ontinyent. Este espacio forma parte del río Clariano, se analiza desde una perspectiva holística en una salida de campo posterior en la que el alumnado investiga aspectos relacionados con el tiempo atmosférico, el suelo, la vegetación, las aguas y el patrimonio cultural y podrá contrastar con las percepciones y conjeturas iniciales que tenía de ese paisaje.

La actividad analizada se integra dentro de los ejercicios de la unidad didáctica: primero cada alumno/a realiza un dibujo del espacio mencionado, al que atribuye cinco palabras (segundo ejercicio) que posteriormente ordena según su importancia en una escala numérica en importancia creciente de 1 a 5, finalmente cada alumno explica lo que ha dibujado recurriendo a las palabras mencionadas en el ejercicio anterior. El análisis de la representación que tiene ese alumnado acerca del clima y paisaje de esa localidad y sus relaciones con el entorno se realiza mediante la interpretación del contenido de sus dibujos y las palabras asociadas a los mismos. Este es un método esencial en la didáctica de las ciencias sociales, ya que favorece la comprensión del 
comportamiento de los sujetos participantes (Yin, 1989). Aunque la interpretación de las palabras clave asociadas a ese paisaje y las representaciones pictóricas del alumnado es conjunta, es preciso establecer algunas consideraciones. Los ejercicios 2.2.B y 2.2.C en los que el alumnado elige y ordena cinco palabras que atribuye al mencionado paisaje corresponden al modelo de test de asociación de palabras (Agüero y Chama, 2009; Navia y Estrada, 2012). Los datos ordenados de esas palabras se han analizado mediante el software Evocation 2005, que ha sido utilizado en otras investigaciones (Lopes, 2010; Silva y Viveiros, 2017) y sigue las orientaciones del Grupo Midi (Flament, 2001), en las que se ha encontrado una aplicación metodológica de la teoría de las representaciones sociales al campo de la didáctica (Domingos, 2000; Saraiva, 2007). Por su parte, la interpretación de las representaciones pictóricas de las preguntas 2.2.D y 2.2.E se ha realizado con la finalidad de conocer cómo expresa el alumnado ese paisaje, siguiendo el enfoque de Duborgel (1981). Son representaciones pictóricas que adquieren la función de esquemas mentales (Kosslyn, 1981; Vara, 2010) y ayudan a conocer el sentido que el alumnado otorga a ese paisaje como espacio subjetivo, tal y como se ha venido haciendo en la geografía de la percepción y del comportamiento con los mapas mentales (Caneto, 2000). En este estudio las representaciones del paisaje se ajustan más a los esbozos de mapas, croquis o dibujos menos elaborados (Escobar, 1992), que se realizan de forma espontánea por parte del alumnado al inicio de la unidad didáctica.

Respecto a la entrevista semiestructurada se atiene al guion que ha sido revisado por un grupo de docentes pertenecientes a universidades iberoamericanas que han conocido previamente los objetivos de esta investigación. La entrevista esta compuesta por tres partes, una primera parte referida a los datos estadísticos, edad, género, tipo de centro, asignatura que imparte, formación académica, nivel y curso. Una segunda parte que se compone de once preguntas sobre la formación, instrucción y práctica como docentes en la explicación del clima y paisaje local. Finalmente, una encuesta de valoración sobre el uso e importancia de los conceptos relacionados con clima y paisaje. El contenido de las entrevistas semiestructuradas se utilizó para comprender los resultados de experimentación de la unidad didáctica, esto es, con la intención de conocer las experiencias y situaciones de aula por parte del profesorado (Taylor y Bodgan, 2000; Travé, 2019). Esto permitió aproximarnos a los elementos que intervienen en la praxis docente y conocer los obstáculos que intervienen en la propuesta didáctica, siguiendo los presupuestos de la investigación-acción en la que se enmarca por corresponder al proyecto Nós Propomos (Claudino et al. 2019). El carácter semi-estructurado de este tipo de entrevistas ha permitido introducir algunas preguntas nuevas durante el desarrollo de las mismas, si bien no se ha alterado el propósito fundamental. La transcripción sigue un sistema complejo en el que se han considerado aspectos prosódicos y los cambios de ideas de los participantes (Onwuegbuzie et al. 2009) para analizar sus respuestas, 
siguiendo el esquema de trabajo de otras investigaciones que han recurrido a esta técnica (García Calvente y Mateo Rodríguez, 2000; García-Ruiz y Lena-Acebo, 2019).

Las entrevistas semiestructuradas, son una técnica que se encuadra en la vertiente procesual del enfoque metodológico de Banchs (2000) y se complementará con la vertiente estructural que engloba los dibujos y la estructura representacional que manifiesta el alumnado. Con todo ello la utilización de un método exploratorio secuencial mixto (Creswell, 2014) dará acceso a la comprensión global de la representación escolar del paisaje a partir de una muestra de tipo no probabilístico o intencional (Otzen y Manterola, 2017).

\subsection{El escenario geográfico. Paisaje fluvial del Clariano: Pou Clar a Pont Nou}

Cuando necesitamos analizar las representaciones sociales de los estudiantes, los escenarios geográficos son lugares que facilitan condiciones singulares para analizar e interpretar ya que los paisajes y el territorio al que pertenecen muestran unas realidades naturales, culturales y socioeconómicas bien definidas (García de la Vega, 2014, p.103).

Ontinyent es un municipio de la provincia de Valencia con un territorio municipal de 12,543 ha. En el que se encuentra el paraje natural protegido del Pou Clar i Serra de l'Ombría que tiene 2.871 ha. El paraje está situado al sur del término municipal y destaca por su alto valor medioambiental. Uno de los nacimientos del río Clariano, verdadero eje vertebrador del municipio, se encuentra en el Pou Clar. Los manantiales de agua llamados "brolladors" conforman junto con las pozas, "pous", excavadas en la piedra calcárea y los "tolls", balsas, una zona de recreo natural donde los lugareños acuden con asiduidad a pasear o bañarse en verano pues el paraje se encuentra a tan solo 3,5 kilómetros de la población. Del Pou Clar hasta el Pont Salt (ver Figura 1), el río discurre entre pozas, terrazas fluviales, meandro, peñas, pendientes, confluyen barrancos, vegetación de ribera y mediterránea, pistas forestales, caminos rurales. Estos tramos de lo que consideramos medio natural se intercalan de otros tramos de río con mayor presencia de la acción humana con mesas, carteles, zonas de recreo, casas de campo abandonadas, cultivos agrícolas, huertos, antiguas construcciones eléctricas, casetas, granjas agropecuarias o caminos asfaltados, zonas de urbanización dispersa, lo denominamos medio natural antropizado.

En el recorrido del río Clariano desde el Pont del Salt hasta el Pont Nou en la zona urbana de Ontinyent, se pueden encontrar alrededor de sus riberas elementos del medio natural y urbano, hídricos, geomorfológicos, estructurales, relacionados con las actividades humanas, con infraestructuras, vegetación, fauna. En este medio urbano cruzado por un río encajonado, se pueden apreciar restos de antiguas casas y fábricas, molinos hidráulicos, puentes que comunican los barrios de Ontinyent que se parten por 
el cauce del río y que permiten desplazarse a los ciudadanos de una parte a otra de Ontinyent y la carretera CV-81.

De forma genérica se puede considerar que aparecen tres medios diferenciados por los elementos que describen sus tramos. Aunque no hay ningún tramo que podamos considerar como puro, entendemos que hay un tramo que llamamos de medio natural donde prevalecen elementos naturales, un segundo tramo donde conviven elementos naturales y antrópicos que llamaremos medio natural antropizado y un tercer tramo que llamamos medio urbano, ya que el río atraviesa completamente la población de Ontinyent por su casco urbano.

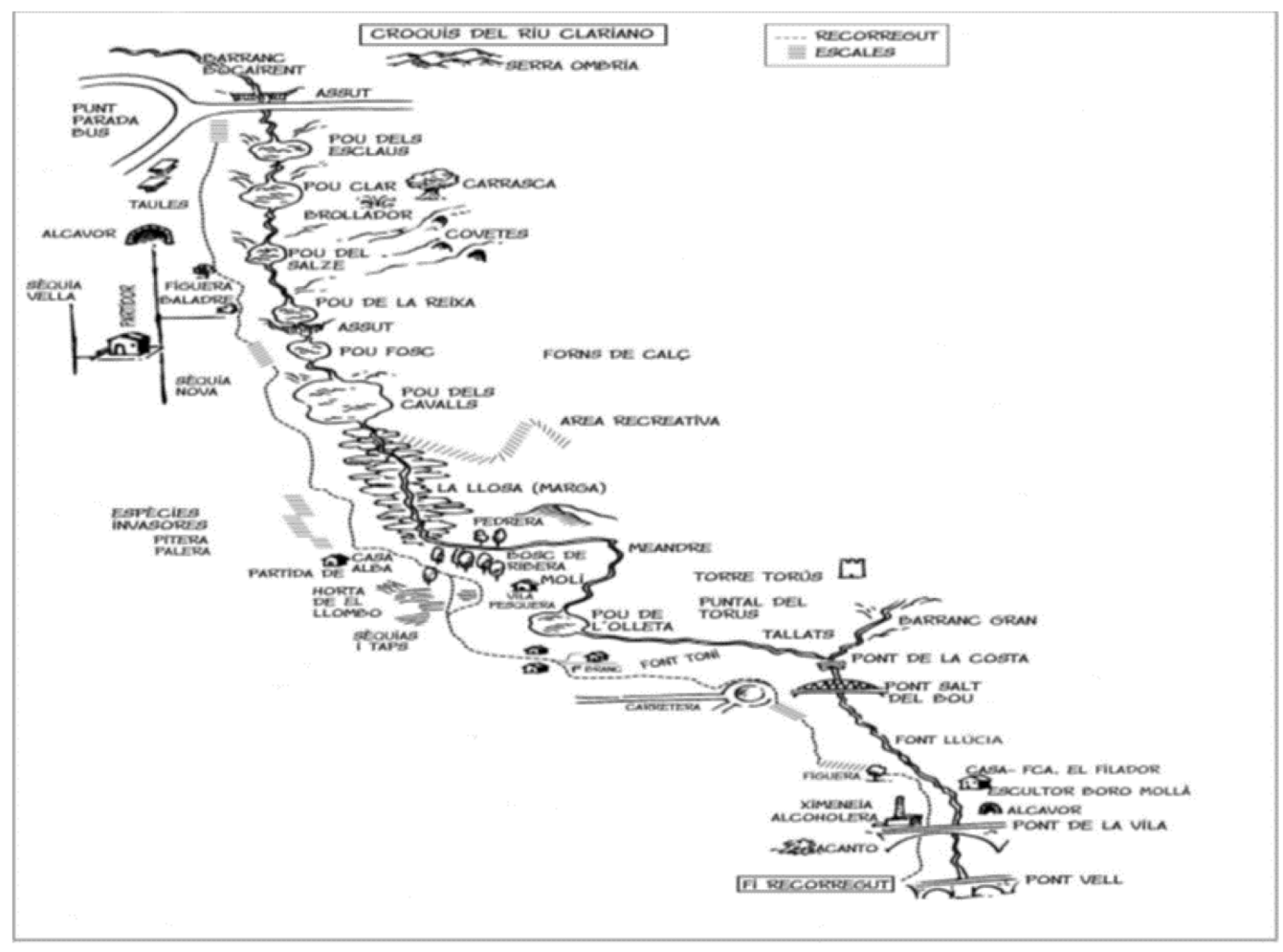

Figura 1. Croquis del paisaje fluvial del río Clariano del Pou Clar al Pont Vell. Fuente: Elaborado por Casañ $\tilde{n}^{3}(2019)$

${ }^{3}$ Croquis inserto en la pàgina 8 del cuaderno de campo titulado "Descobrint el paisatge i els problemes socioambientals del riu Clariano”, de B. Campo y J. Casañ (coords.) en 2019, de 36 páginas, como material escolar editado por la empresa Actio con fondos del proyecto de Innovación Docente de la Universidad de Valencia UV-SFPIE_GER18-8500040. 


\section{ANÁLISIS Y DISCUSIÓN DE LOS DATOS}

\subsection{La estructura representacional: una cosmovisión del paisaje del río Clariano}

Los primeros datos corresponden a las palabras analizadas por el software Evocation 2005 y proporcionan información sobre la estructura del contenido representacional del concepto paisaje en el tramo correspondiente del río Clariano en el que se llevó a cabo la intervención didáctica con posterioridad a la realización de este ejercicio.

El agua y la vegetación (F 23) constituyen la parte más prominente del núcleo central de la representación del paisaje. Esto significa que esos dos elementos (agua y vegetación) aparecerán con mayor frecuencia en las explicaciones del alumnado, que complementan estas palabras con otras similares (río y plantas), que completan la cosmovisión natural de ese paisaje. El núcleo central contiene un elemento descriptivo (adjetivo bonito), que valora la composición de los elementos naturales que componen el paisaje. La totalidad de estas cinco palabras que componen el núcleo central de la representación tienen un rango medio que ronda el valor de 1,8 y 2,0. Estos valores indican que han sido las palabras evocadas en primer lugar y, por tanto, con mayor significación por el alumnado si tenemos en cuenta que 2,5 es el rango medio de evocación (o posición que otorga el alumnado a las palabras) que se obtiene teniendo en cuenta que de las 5 palabras evocadas, el valor 1 corresponde a la que presenta mayor relevancia y 5 a la que menos. Siguiendo con la tabla 1, el concepto puente constituye un punto de inflexión entre el núcleo central y los elementos periféricos. Los puentes son un elemento que por su menor rango (3.33) ha sido evocado más tardíamente por el alumnado, lo que alude a una escasa significación en la posición que ocupa esa palabra dentro de la estructura representacional. En cuanto a los elementos periféricos, las palabras vuelven a ahondar en la concepción naturalista del paisaje (árboles, animales, naturaleza, fauna...), como se aprecia en la celda inferior izquierda de la tabla 1, que representa los valores más consistentes de la periferia representacional.

\begin{tabular}{lcrlcr}
\hline & Nucleo central & \multicolumn{3}{c}{ Elementos intermedios } \\
\hline Agua & $\mathrm{F} \geq 12$ & $\mathrm{R}<2.5$ & $\mathrm{~F} \geq 12$ & $\mathrm{R} \geq 2.5$ \\
Vegetación & 23 & 1.826 & Puente & 15 & 3.333 \\
Bonito & 23 & 2.000 & & \\
Rio & 20 & 2.200 & & \\
Plantas & 14 & 1.929 & & \\
\hline
\end{tabular}




\begin{tabular}{lcclcc}
\hline \multicolumn{3}{c}{ Elementos periféricos } & \multicolumn{3}{c}{ Elementos periféricos } \\
\hline Arboles & $\mathrm{F} \leq 12$ & $\mathrm{R}<2.5$ & $\mathrm{~F} \leq 12$ & $\mathrm{R} \geq 2.5$ \\
Animales & 11 & 2.091 & Peces & 9 & 3.000 \\
Naturaleza & 9 & 1.889 & Ríos & 5 & 3.200 \\
Fauna & 7 & 1.875 & Rocas & 8 & 3.500 \\
Sierra & 7 & 1.714 & Piedras & 8 & 2.875 \\
Verde & 6 & 1.714 & Puentes & 8 & 4.000 \\
Turístico & 5 & 2.167 & Pozos & 6 & 2.833 \\
& & 2.400 & Tranquilidad & 4 & 3.000 \\
& & & Alegría & 4 & 2.500 \\
\hline
\end{tabular}

TABLA 1. Estructura representacional del paisaje entre el Pou Clar y el Pont Nou de Ontinyent. Fuente: Elaboración propia a partir del software Evocation 2005. F corresponde a la frecuencia $\mathrm{R}$ al rango medio de evocación (oscila entre 1 y 5 )

$\mathrm{Si}$ atendemos a los resultados según los institutos participantes, Centros A y B, se observa que la tendencia a valorar el paisaje como bonito no ofrece grandes diferencias. No obstante, se aprecia que en uno de los institutos de ESO de la muestra (Centro A) la representación de ese paisaje es más global y se apoya en elementos genéricos de corte abiótico. Este alumnado otorga gran importancia al agua y su valoración en medio de un escenario natural en el que nombran el río. Por su parte, en el otro instituto (Centro B), la vegetación, las plantas y los árboles son parte del núcleo duro de su cosmovisión del paisaje, en la que el agua es un elemento importante, aunque no tanto como en el caso anterior.

En relación con el Objetivo 1, el alumnado no contempla ningún concepto, elemento directo relacionado con el clima, como podrían ser sol, nubes, cielo, calor, frio, etc. La relación se establece por medio de otros elementos que representan la acción del clima en el paisaje como agua, vegetación, río, plantas, naturaleza.

Por medio de los resultados parciales de cada Centro, A y B, se observa en ambos la importancia del concepto agua. Sin embargo, se rige por el orden siguiente: el Centro A establece su prioridad por el concepto naturaleza mientras el centro B lo hace por vegetación.

\subsection{Representaciones pictóricas del escenario geográfico}

Para completar el desarrollo del Objetivo 1, se analizan los dibujos realizados sobre el paisaje fluvial propuesto. Para ello, primero se clasifican los elementos que pintan en los dibujos según pertenecen al componente del paisaje. Estos componentes del paisaje fluvial del río Clariano y sus respectivos elementos son conceptos y relaciones que comprende un estudiante que ha terminado la Educación Primaria (Tabla 2). 


\begin{tabular}{ll}
\multicolumn{1}{c}{$\begin{array}{c}\text { Componentes } \\
\text { del paisaje }\end{array}$} & \multicolumn{1}{c}{ Elementos que plasman en los dibujos } \\
\hline Clima & sol, nubes, cielo \\
Hídrico & agua, río, manantial, riachuelo, fuente, poza \\
Relieve/suelo & sierra, montaña, pendiente, roca, piedra, tierra, barranco \\
Vegetación & plantas, árboles, arbustos \\
Estructural & $\begin{array}{l}\text { infraestructuras, edificios, caminos y carreteras, urbanizaciones, tendidos } \\
\text { eléctricos, zonas de cultivo, fábricas abandonadas, acequias, repartidores }\end{array}$ \\
Social & zonas de recreo, picnic, baño, deporte, señales, indicadores, bancos \\
Fauna & patos, aves, peces \\
\hline
\end{tabular}

TABLA 2. Elementos que aparecen los dibujos del paisaje fluvial. Fuente: Elaboración propia

La acción antrópica en el paisaje la dividimos en dos componentes, estructural y social. Una vez clasificados los elementos de cada componente del paisaje, se establece la frecuencia con que aparecen en cada dibujo (ver Figura 2), de esta manera obtenemos lo que llamamos Predominio, es decir, el componente que contiene más elementos en el dibujo que se representa el paisaje.

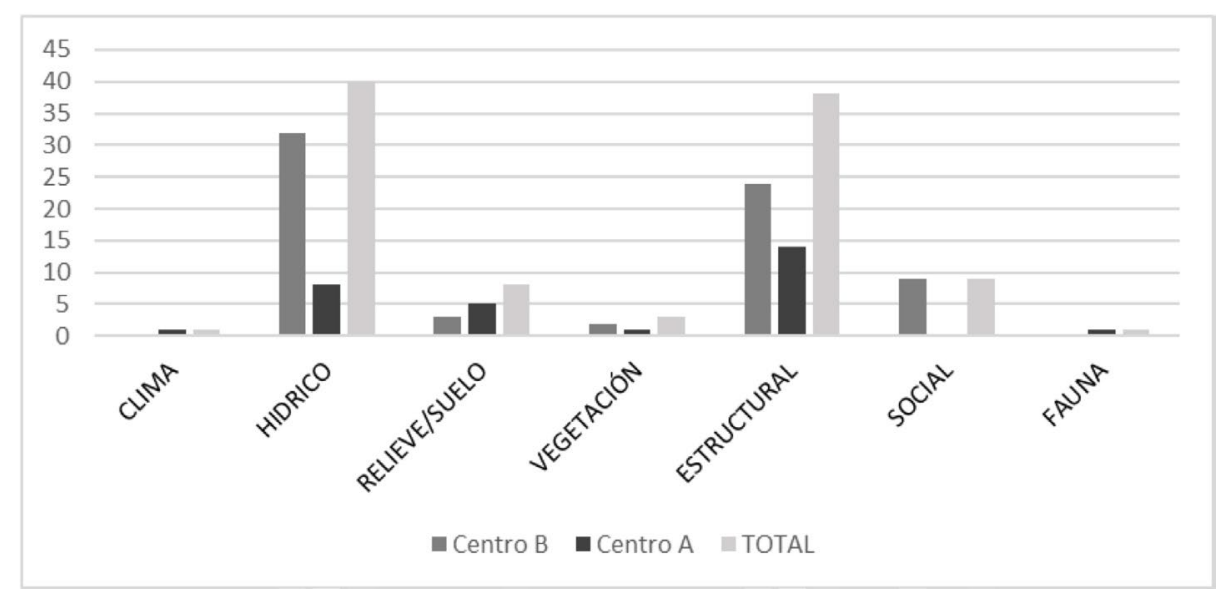

Figura 2. Predominio de componentes que representan el paisaje por Centros.

Fuente: Elaboración propia 
Tanto en el Centro B como en el A, el paisaje dibujado tiene un Predominio de componentes estructural e hídrico.

Una vez establecidos los componentes que aparecen en el paisaje fluvial de cada dibujo, lo relacionamos con los tipos de medio que describen el recorrido. Entendiendo como Medio Natural si no aparecen en los dibujos los componentes social y estructural, Medio Natural Antropizado si aparecen componentes físicos y humanos, y Medio Urbano cuando aparecen componentes estructural y social, y posiblemente algún otro físico. En la figura 3 se observan ejemplos de representaciones que hemos clasificado según el medio, siendo A una representación del medio natural, B del medio natural antropizado y $\mathrm{C}$ del medio urbano.
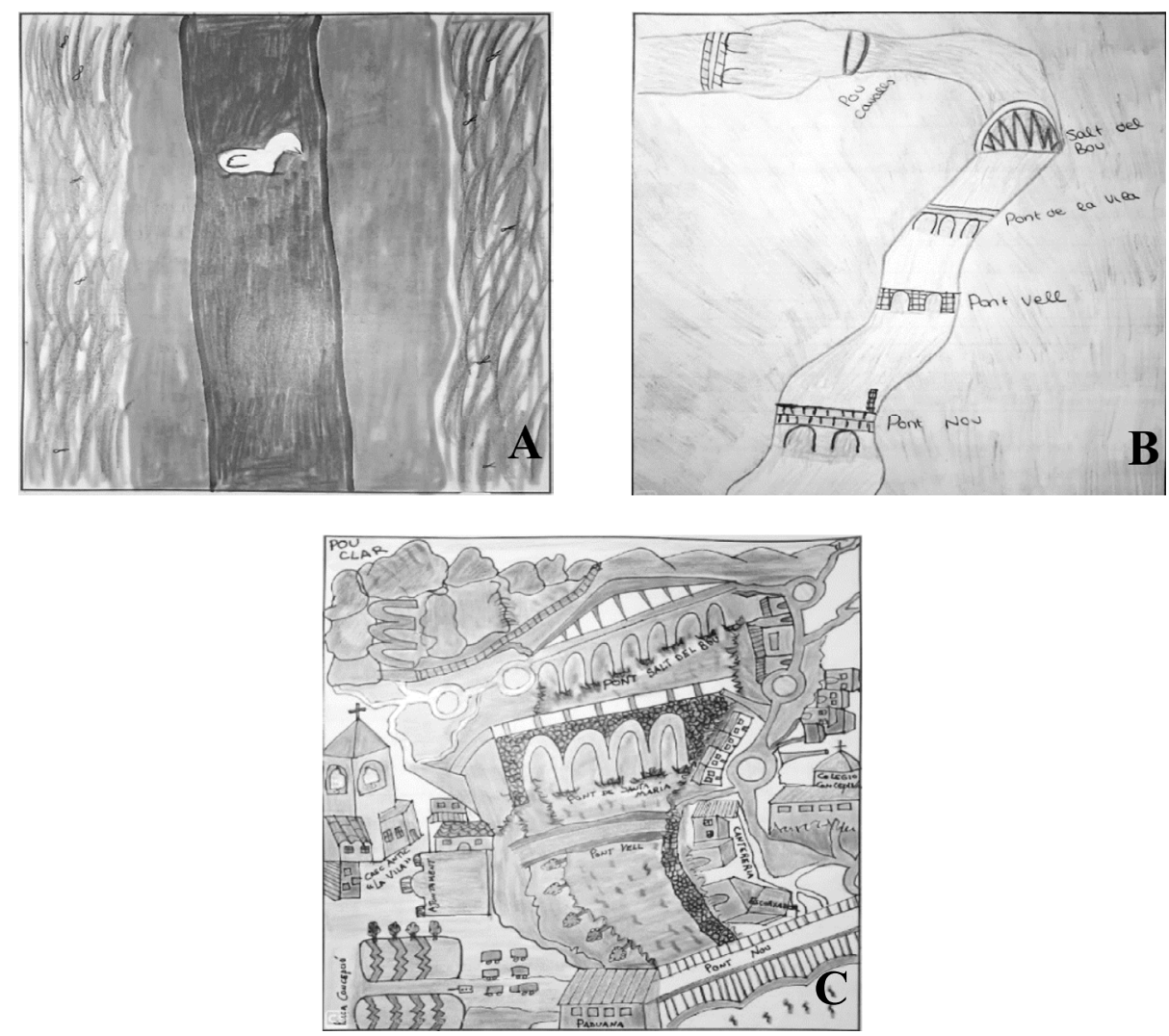

Figura 3. Dibujos de tipos de medio del paisaje del río Clariano. Fuente: elaborado por estudiantes participantes en el estudio ${ }^{4}$

${ }^{4}$ Corresponden a los participantes de los centros A y B de la muestra. 
A. el dibujo solo contiene elementos físicos del medio natural, agua, río, ribera, vegetación, pato (fauna);

B. aparece el curso del río con la mayoría de puentes que lo cruzan, destacando los cuatro puentes que pertenecen al casco urbano, Nou, Vell, de la Vila y Salt del Bou, dibuja las formas y estructuras de los puentes. Sin embargo, no aparecen otros elementos estructurales o sociales por lo que se ha clasificado como medio natural-antropizado;

C. el dibujo es exponente de un medio urbano en el que, además de contemplar la diversidad de elementos estructurales y sociales, se muestran el curso de río y una visión panorámica en perspectiva del paisaje que intenta abarcar toda su extensión. Cabe destacar la inclusión de elementos de todos los componentes del paisaje.

En base al total de dibujos obtenidos, se ha realizado la siguiente relación porcentual (ver tabla 3) que refleja en qué medida los alumnos han representado más un medio u otro. Es decir, qué porcentaje de dibujos corresponde a un medio natural, qué porcentaje a uno urbano, o qué proporción a un medio natural antropizado. Esto indica la idea de medio que predomina en el alumnado de cada centro y, en el conjunto formado por el total de la muestra.

\begin{tabular}{lccc}
\hline Estudiantes & Natural & $\begin{array}{c}\text { Natural } \\
\text { Antropizado }\end{array}$ & Urbano \\
\hline Centro A & $36 \%$ & $32 \%$ & $32 \%$ \\
Centro B & $15 \%$ & $56 \%$ & $29 \%$ \\
Total & $22 \%$ & $48 \%$ & $30 \%$ \\
\hline
\end{tabular}

TABLA 3. Representaciones del paisaje como Medio. Fuente: Elaboración propia

Nótese el grado de representación que tienen los distintos medios entre el alumnado: cabe destacar que, aunque en el centro A el medio Natural es el que cuenta con un mayor grado de representación (36\%), puede verse un cierto grado de igualdad en las representaciones. En cambio, vemos cómo en el Centro B es el medio natural antropizado el que más representación tiene, correspondiéndose con un 58\% de los dibujos.

En relación al Objetivo 1, según los análisis realizados en el epígrafe 4.1, las palabras que el alumnado elige para definir el paisaje revelan que en la estructura representacional no se consideran términos asociados al concepto del clima La relación con el clima aparece de forma residual o indirecta. Respecto al análisis de los dibujos del epígrafe 4.2, solo dos participantes tienen el componente "clima" como predominante, hay once estudiantes que representan en sus dibujos el clima, pero 
como componente no predominante. Por tanto, solo un 10,5\% de los estudiantes de la muestra contemplan las tres dimensiones del espacio euclídeo, dibuja sobre un plano tridimensional y aparecen además de otros elementos del paisaje, el horizonte, el cielo, las nubes o el sol.

Para finalizar el análisis del objetivo 1 se muestran en la figura 4, dos representaciones del clima en el paisaje fluvial:

A. en el dibujo se observa el predominio del clima, aparecen los elementos sol y cielo, también aparece fauna (aves) y suelo. En su estructura representacional el estudiante elige las palabras calor, pájaros, agua, aire y alegría. Nótese la inclusión de otros elementos relacionado con el clima como calor, aire y agua. Además de ser uno de los ejemplos en toda la muestra de una concepción del paisaje fluvial que corresponde al medio natural pues solo parecen elementos del medio físico. Cuando tiene que explicar lo que ha dibujado dice brevemente: "en el dibujo he puesto las cosas que me transmite ese paraje natural con su naturaleza".
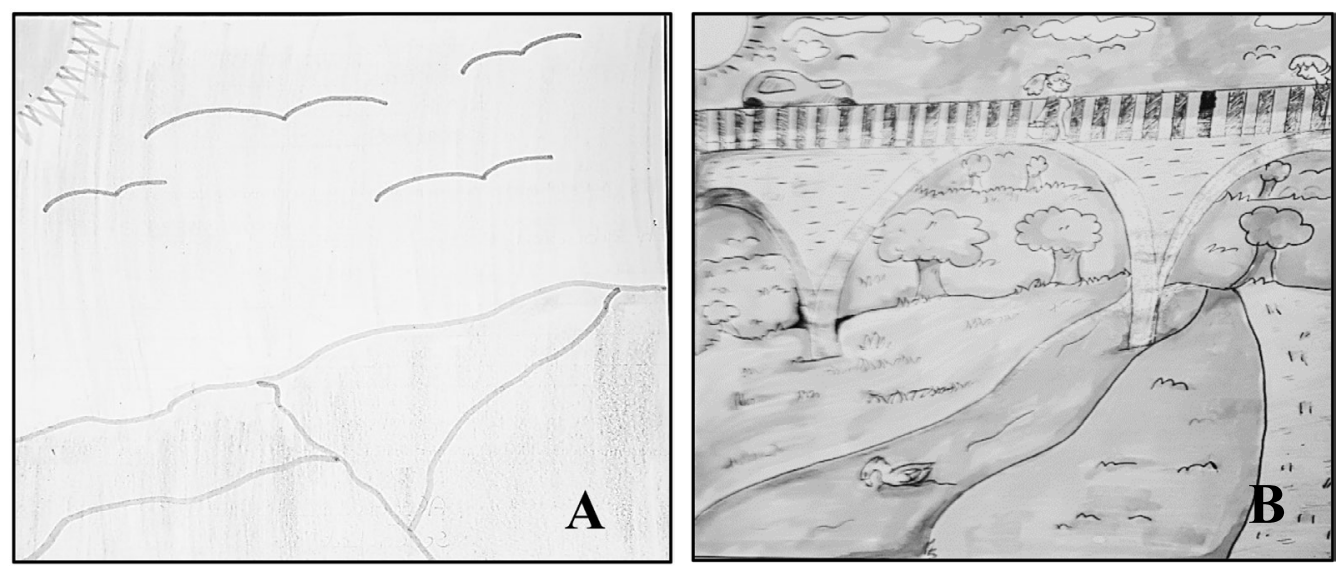

FiguRA 4. Dibujos con predominios climáticos. Fuente: Dibujos realizado por los participantes del Centro A

B. en el dibujo, los elementos del clima como nubes cielo y sol aparecen junto a elementos de componente hídrico (agua, río), vegetación (árboles, hierbas, verde), fauna (aves en el cielo y en el agua un pato), estructural (puente, camino). Social (personas desplazándose, coche). Las palabras que elige son por este orden vegetación, ríos, gente, fauna y tranquilidad. En la explicación que realiza se constata la visión que tiene del paisaje fluvial y como conceptualiza mediante 
su representación del espacio que en este caso es vivido y percibido. El dibujo es una zona donde el río atraviesa el casco urbano de Ontinyent por un puente que está cercano al instituto donde estudia, aunque está en la zona urbana, su representación y explicación se asemejarían a un medio natural antropizado, siendo un medio urbano:

"He dibujado básicamente el Pont Nou de Ontinyent, un día cualquiera de primavera, verano u otoño. Hay gente caminando y está todo representado como un día normal allí. El río está lleno y el agua está transparente y refrescante. Hay árboles y un pato. También hay un camino".

\subsection{Las representaciones de los docentes ante la explicación del clima y paisaje}

En este punto se desarrolla el análisis que pertenece al Objetivo 2 del estudio. Para ello se han realizado 14 entrevistas a docentes cuyo rasgo más definido de este grupo es su variedad e interdisciplinaridad.

Entre las cuestiones realizadas en la entrevista analizamos las que hacen referencia a qué conceptos entendían eran más importantes para explicar el clima y el paisaje y cómo valoraban el conocimiento de esos conceptos (ver resultados figura 5).

El rango de uso de un concepto es sobre 14 y se corresponde con el número de docentes que participan, mientras que la valoración que hacen sobre la menor o mayor importancia de un concepto para sus explicaciones del clima o clima local, se corresponde a una escala de 1 a 4 , siendo 1 si valoran muy poco ese concepto y 4 si lo valoran mucho.

El cuestionario contemplaba otras cuestiones que se relacionaban con estos usos y valoraciones. Por ejemplo, si utilizaban ejemplos o datos de Ontinyent para explicar el clima o el clima local, o que tipo de recursos utilizaban para sus explicaciones. La mayoría responde que lo más frecuente es el libro de texto y alguna vez noticias o hechos sobre el tema, pero no preferentemente de la localidad. Analizando los resultados de la figura 4 y las respuestas, se infiere que la mayoría utiliza los conceptos de tiempo atmosférico, clima, cambio climático, efecto invernadero, paisaje y Dana (en Ontinyent con regularidad en los últimos años con fuertes inundaciones).

5 Las explicaciones de cada estudiante sobre el dibujo que realiza son traducidas y transcritas del valenciano. 


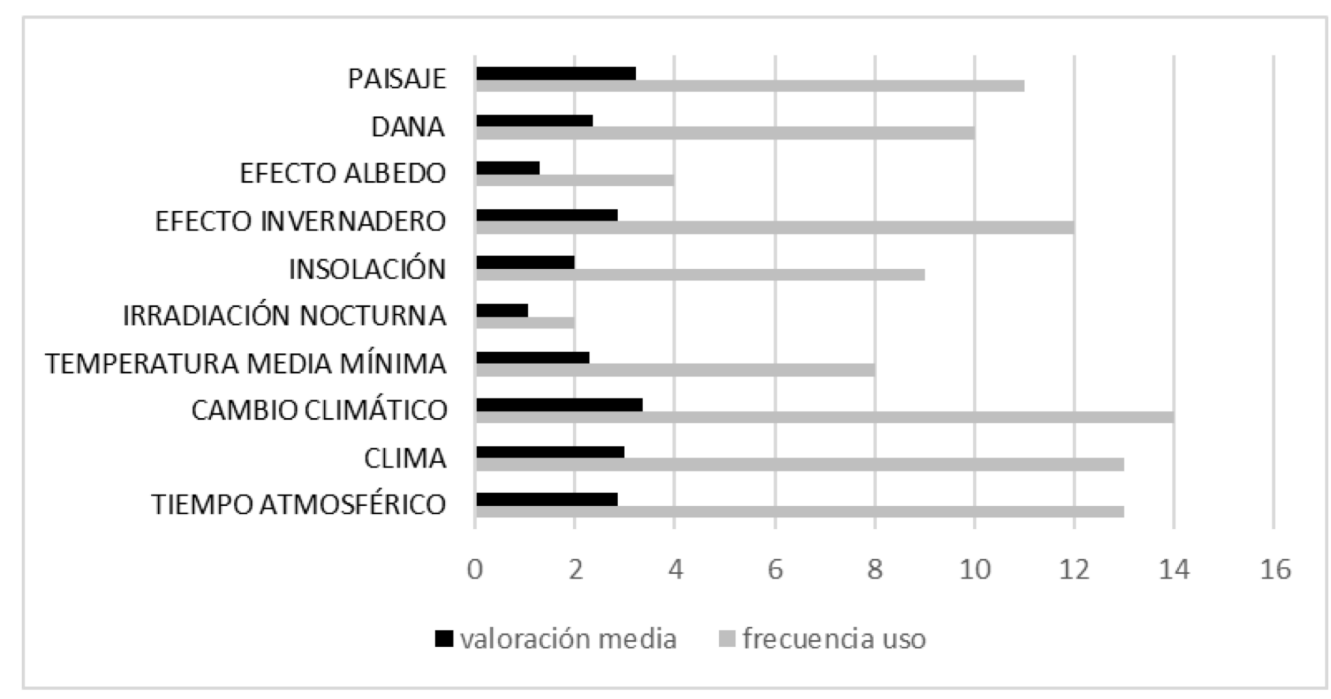

Figura 5. Usos y valoraciones de los docentes a conceptos que explican el clima. Fuente: Elaboración propia

Se valora de poca importancia y no se explica la insolación, la irradación nocturna o la temperatura media. Con estas premisas se infiere que:

- Los docentes se guían principalmente por los libros de texto, esto coincide con los conceptos que se incluyen en los libros, los que utilizan y les parecen importantes. Esto se observa claramente al usar y valorar más el efecto invernadero que la temperatura media mínima, la irradiación nocturna o la insolación, siendo estas últimas bases fundamentales para una explicación de lo que sucede con el clima hoy día.

- En las explicaciones del clima y clima local consideran importante el uso del concepto paisaje sin embargo no utilizan ejemplos de datos, hechos o situaciones propias de la localidad, excepto de la Dana que sufren cada año.

\subsection{Los fundamentos de los docentes}

El docente del centro A es maestro y licenciado en geografía e historia, imparte clases en $1^{\circ}$ ESO de Ciencias Sociales en un instituto público. El docente del centro $\mathrm{B}$ es licenciado en biología e imparte clases de biología y matemáticas en un centro concertado. Estos docentes se van aclimatando a los problemas de la praxis diaria y los obstáculos. Veamos un ejemplo de las contestaciones de cada docente a una misma pregunta. 
Cuando tiene que tratar de explicar el clima, el cambio climático y el paisaje en Ontinyent ¿qué problemas encuentra para desarrollar las explicaciones a su alumnado?

Docente Centro A: Antes de experimentar la Unidad didáctica no tenía información y la que había no la buscaba. Esto debe de hacerse dentro de un equipo y yo estaba impedido. En el año 2011 tenía una alumna, hija del jefe de estudios de ciclos, mi compañero pensaba que en mis clases los alumnos no aprendían. Yo no seguía el libro ni soy muy tradicional. En el mes de febrero me llamó a consulta el director y el jefe de estudios de ESO para comunicarme que había quejas por parte de algunos padres. Esto era un eufemismo. Le contesté que a partir del día siguiente seguiría el libro y que disculparan.

Docente Centro B: En primer lugar, el alumnado tiene muchos conceptos idealizados, erróneamente construidos por la cantidad de información poco filtrada que tienen. Hay que reconstruir de nuevo los conocimientos previos y reforzarlos.

El análisis de la entrevista y el Objetivo 2, se sintetiza en la siguiente tabla 4.

\begin{tabular}{|c|c|c|c|}
\hline \multicolumn{2}{|c|}{$\begin{array}{c}\text { Enseñanza } \\
\text { clima -paisaje }\end{array}$} & Docente del centro A & Docente del centro B \\
\hline \multicolumn{2}{|c|}{ Teorías en que se apoya } & $\begin{array}{l}\text { Teorías piagetianas. } \\
\text { Geografía de la percepción }\end{array}$ & $\begin{array}{l}\text { Constructivismo } \\
\text { Dewey, experimentación }\end{array}$ \\
\hline \multicolumn{2}{|l|}{ Metodología } & ABP-problemas & ABP-Proyectos \\
\hline \multicolumn{2}{|c|}{$\begin{array}{l}\text { Contenidos se } \\
\text { relacionan con }\end{array}$} & $\begin{array}{l}\text { El río y sus problemas, Relación } \\
\text { ecológica. Participación } \\
\text { ciudadanía } \\
\text { Valorar y disfrutar del medio }\end{array}$ & $\begin{array}{l}\text { Interacción con el medio } \\
\text { Interdisciplinaridad. }\end{array}$ \\
\hline \multirow[t]{2}{*}{$\begin{array}{l}\text { Conceptos } \\
\text { que utiliza }\end{array}$} & $\begin{array}{l}\text { Poco o } \\
\text { nada }\end{array}$ & $\begin{array}{l}\text { Clima, } \\
\text { Tiempo atmósférico } \\
\text { Cambio Climático } \\
\text { Efecto invernadero } \\
\text { Paisaje }\end{array}$ & $\begin{array}{l}\text { Clima, } \\
\text { Tiempo atmosférico } \\
\text { Temperatura Media Mínima } \\
\text { Paisaje }\end{array}$ \\
\hline & $\begin{array}{l}\text { Bastante } \\
\text { o mucho }\end{array}$ & $\begin{array}{l}\text { Temperatura Media Mínima } \\
\text { Irradiación nocturna } \\
\text { Insolación } \\
\text { Dana } \\
\text { Efecto Albedo }\end{array}$ & $\begin{array}{l}\text { Cambio climático } \\
\text { Efecto invernadero } \\
\text { Irradación nocturna } \\
\text { Insolación } \\
\text { Dana } \\
\text { Efecto Albedo }\end{array}$ \\
\hline
\end{tabular}

TABla 4. Modelo docente en la explicación del clima y paisaje. Fuente: Elaboración propia 
Los cambios metodológicos que pretenden desarrollar estos docentes se topan con dos tipos de rechazos: en el centro A, el rechazo de la comunidad educativa a planteamientos constructivistas e innovadores y, en el centro B el que enfrenta a los estudiantes a trabajar con otra metodología, en ambos casos supone la constatación del inmovilismo escolar, el rechazo a salir de la zona de confort.

\section{CONCLUSIONES:}

En las representaciones sociales que tiene el alumnado del paisaje del río Clariano, el concepto clima no es un componente destacable. Los elementos del clima aparecen en un porcentaje no mayor del 10,5\% de todos los dibujos realizados. En la estructura representacional el clima tiene carácter residual. Un resultado similar sucede cuando se analizan los dibujos dos participantes tienen el componente "clima" como predominante en sus dibujos, solo hay once estudiantes que representan en sus dibujos el clima. solo un $12 \%$ de los estudiantes de la muestra contemplan las tres dimensiones del espacio euclídeo, dibujan sobre un plano tridimensional sus representaciones. El horizonte, el cielo, las nubes o el sol, el espacio de la atmósfera aparece de forma residual junto con otros componentes.

En general predomina el concepto agua, el componente hídrico y el estructural (antrópico), se aprecian diferencias entre los Centros. uno contiene con más frecuencia la idea de un paisaje relacionado con la naturaleza y el otro relacionado con la vegetación. Esto se relaciona con las dinámicas de los docentes de cada centro y que son consecuentes con el pensamiento educativo que tienen, la formación, modelo didáctico o la metodología que utilizan.

Las explicaciones de los docentes sobre como usan y valoran los conceptos en la explicación del clima indica la necesidad de romper con las rutinas y tradiciones que impiden una formación permanente adaptada a los problemas ambientales actuales. De esta forma los docentes estarían preparados para explicaciones más complejas sobre el clima y su evolución hoy día, igualmente podrían formarse en el espacio cotidiano, local, como fuente explicativa de los hechos ambientales.

Consideraciones finales:

- los datos obtenidos mediante la combinación de instrumentos como Evocation, dibujos y la entrevista semiestructurada, nos reafirman en la utilidad de estas herramientas para conocer las representaciones sociales de una población escolar concreta, pues ofrecen una oportunidad para calibrar la conceptualización y descripción mental que tienen los estudiantes de ese paisaje y la manera de pensar del docente que rige sus actuaciones en la praxis. 
- las ideas expresadas por el profesorado sobre su visón de la acción docente y formativa ante los problemas ambientales nos sugieren la posibilidad de implicar al profesorado en una experiencia basada en la investigación-acción, pues, aunque no era un elemento central del estudio, se ha podido constatar en algunos casos, los docentes introducen cambios en la metodología docente a partir de su experiencia lo que coincide con los planteamientos de Lewin y Stenhouse (Elliot, 2000).

- a partir de los resultados, se infiere que el análisis de la información recogida por diferentes técnicas sirve para obtener aproximaciones de la realidad que se quiere transformar, como son:

- reconocer las concepciones con las que llega el alumnado de Educación Primaria a Secundaria, obtener pistas sobre el conocimiento del contenido disciplinar que tienen del clima y la geografía.

- verificar las dificultades del profesorado para quebrar las tradiciones y rutinas escolares

La idealización del paisaje y la escasa presencia del clima en las representaciones del alumnado junto con las dificultades de los docentes en su conocimiento disciplinar y su práctica nos conmina a quebrar las tradiciones y rutinas escolares para afrontar mejor las explicaciones de las transformaciones ambientales.

\section{BIBLIOGRAFÍA}

Agüero, A. \& Chama, M. (2009). Arriesgando la palabra: cultura y psicoanálisis. Buenos Aires: Autores de Argentina.

Álvarez, M. E. (2013). La neurociencia en las ciencias socio-humanas: una mirada transdisciplinar. Ciencias Sociales y Educación, 3, 153-166.

Arto, J. M. (2010). El cambio climático narrado por alumnos de educación primaria y secundaria: propuesta de análisis para dibujos y textos. In Investigar para avanzar en la Educación Ambiental. Doctorado Interuniversitario de Educación Ambiental (pp. 11-29). Madrid: Organismo Autónomo Parques Nacionales. Ministerio de Medio Ambiente y Medio Rural y Marino.

Banchs, M., (2000). Aproximaciones procesuales y estructurales al estudio de las representaciones sociales. Papers on Social Representations. Textes sur représentations sociales, 9, 310-315.

Barraza, L. (2000). Educar para el futuro. En busca de un nuevo enfoque de investigación en la Educación Ambiental. Memorias del Foro Nacional de Educación Ambiental (pp. 253-260). México: UUA, SEP y SEMARNAP. 
Campo, B., Castellà, M., Martínez, M. \& García-Monteagudo, D. (2019). Nosaltres Proposem: què fer amb el paisatge del riu Clariano? Valencia: Nau Llibres.

Campo, B., García-Monteagudo, D. \& Souto, X. M. (2019). Tradiciones escolares en la educación geogràfica, impugnar sus rutines para favorecer la innovación”. In D. Parra y C. Fuertes (Coords.), Reinterpretar la tradición, transformar las prácticas (pp 45-72). Valencia: Tirant Humanidades.

Caneto, C. (2000). Geografía de la percepción urbana. ¿Cómo vemos la ciudad? Buenos Aires: Lugar.

Capel, H. (1973). Percepción del medio y comportamiento geográfico. Revista de Geografía, 7, 58-150.

Casas, Ma ${ }^{\mathrm{a}}$, Erneta, L. \& Puig, J. (2018). La encuesta como herramienta para conocer las ideas previas sobre paisaje del alumnado de ESO: una experiencia piloto en Navarra. Didáctica Geográfica, 19, 47-76. https://doi.org/10.21138/DG.416

Casas, Ma., Puig, J. \& Erneta, L. (2017). El paisaje en el contexto curricular de la LOMCE: una oportunidad educativa: ¿aprovechada o desaprovechada?" Didáctica Geográfica, 18, 39-68.

Cavalcanti. L. (2010). A geografia e a realidade escolar contemporânea: avanços, caminhos, alternativas. Anais do I Seminário Nacional: Currículo em movimientoPerspectivas Atuais. Belo Horizonte.

Claudino, S. et al. (2019). Geografia, Educação e Cidadania. Lisboa: ZOE/Centro de Estudos Geográficos, Instituto de Geografia e Ordenamento do Território da Universidade de Lisboa.

Creswell, J.W. (2014). Research Design: Qualitative, Quantitative and Mixed Methods Approaches. Research design Qualitative quantitative and mixed methods approaches. London: Sage Publications.

Domingos, M. (2000). Habitus e representações sociais: questões para o estudo de identidades coletivas. In A.S.P., Moreira y D.C. Oliveira, (Orgs.). Estudos interdisciplinares de representação social (pp.117-159). Goiânia: AB

Duborgel, B. (1981). El dibujo del niño. Estructuras y símbolos. Barcelona: Ediciones Paidós.

Elliot, J. (2000). La investigación-acción en educación. $4^{\mathrm{a}}$ ed. Madrid: Morata.

Escobar, F. (1992). El esquema cognitivo del espacio urbano. In J. Bosque (Ed.) Prácticas de la geografía de la percepción y de la actividad cotidiana (pp. 54101). Barcelona: Oikus. 
Fernández, J. (2016). La pintura como recurso didáctico para el maestro de primaria en el estudio del espacio geográfico: el ejemplo del paisaje del viñedo". Didáctica Geográfica, 17, 39-62.

Flament, C. (2001). Estrutura e dinâmica das representações sociais. In D. Jodelet (Org.). As representações sociais (pp. 173-186). Rio de Janeiro: EdUERJ.

García Calvente, M. M., \& Mateo Rodríguez, I. (2000). El grupo focal como técnica de investigación cualitativa en salud: diseño y puesta en práctica. Atención Primaria, 25 (3), 181-186. https://doi.org/10.1016/S0212-6567(00)78485-X

García de la Vega, A. (2011). El paisaje un desafío curricular y didáctico. Revista de didácticas específicas, 4, 7-26.

García de la Vega, A. (2014). El pensamiento crítico en el análisis e interpretación de las representaciones sociales del paisaje. In R. Martínez y E. M ${ }^{\text {a }}$ Tonda (Eds.). Nuevas perspectivas conceptuales y metodológicas para la educación geográfica (pp.93108). Murcia: Asociación de Geógrafos Españoles.

García-Monteagudo, D. (2019). La representación social del medio rural: un análisis desde la geografía escolar. Tesis doctoral inédita. Valencia: Universitat de Valencia.

García-Morís, R. (2015). La obra La recogida de la manzana como pretexto para la lectura e interpretación del paisaje tradicional a través de una fuente iconográfica: un estudio con alumnado de $2^{\circ}$ de Bachillerato. Didáctica Geográfica, 16, 115-133.

García-Ruiz, Ma..E. \& Lena-Acebo, F.J. (2019). Movimiento Fablab: diseño de investigación mediante métodos mixtos. OBETS, Revista de Ciencias Sociales, 14 (2), 373-406. https://doi.org/10.14198/OBETS2019.14.2.04

García Pérez, F. (2000). Los modelos didácticos como instrumento de análisis y de intervención en la realidad educativa. Biblio 3W. Revista Bibliográfica de Geografía y Ciencias Sociales, 207.

Gómez, J. (2013). Del patrimonio paisaje a los paisajes patrimonio. Documents d'Anàlisi Geogràfica, 59 (1), 5-20. https://doi.org/10.5565/rev/dag.48

Guerra, P. (2018). Clima y tiempo en Ontinyent. Valencia: Universitat de Valencia.

Jaén, M. \& Barbudo, P. (2010). Evolución de las percepciones medioambientales de los alumnos de Educación Secundaria en un curso académico. Revista Eureka sobre Enseñanza y Divulgación de las Ciencias, 7, 247-259.

Kosslyn, S. (1981). El medio y el mensaje en las imágenes mentales: una teoría. Revisión psicológica, 88 (1), 46-66.

Liceras, A. (2003). Observar e interpretar El paisaje. Estrategias didácticas. Granada: Grupo Editorial Universitario. 
Lopes, M. E. (2010). Praxiologia, representação social de menopausa e práticas educativas de enfermeiras na estratégia saúde da família. (Tesis doctoral no publicada). Río Grande do Norte: Universidade Federal do Río Grande do Norte.

Maderuelo, J. (1996). Introducción: el paisaje. In El Paisaje, Actas II Curso Arte y Naturaleza (pp. 9-12). Huesca: Diputación de Huesca.

Marrón, M. J. (2011). Enseñar y aprender Geografía apartir de distintos leguajes.Una experiencia de trabajo por proyectos para estudiar el clima de España a partir de los refranes. Anales de Geografía, 31 (1), 107-123.

Martínez, M. \& Campo, B. (2017). Saber geografía mediante un problema escolar: ¿nos seguiremos bañando en el Pou Clar? In D. García, S. Martínez y X. Souto, (Coords.). Las buenas praxis escolares: investigar desde la práctica del aula (pp 141-152). Valencia: Nau libres.

Martínez,L. \& Olcina, J. (2019). La enseñanza escolar del tiempo atmosférico y del clima en España: currículo educativo y propuestas didácticas. Anales de Geografía, 39 (1), 125-148. https://doi.org/10.5209/aguc.64680

Martínez de Pisón, E. (2016). Miradas sobre el paisaje. Madrid: Biblioteca Nueva.

Martínez, R. \& López, J. (2016). La enseñanza de la climatología en los manuales escolares de ciencias sociales en Educación Primaria, In R. Sebastiá y E. Tonda, (Eds.). La investigación e innovación en la enseñanza de la Geografía (pp. 245258). San Vicente del Raspeig: Universidad de Alicante.

Morote, A., Campo, B. \& Colomer, J. (2019). El conocimiento del cambio climático en los futuros docentes de Educación Primaria. Una Experiencia de conocimientos previos a partir de la enseñanza de las ciencias sociales. In VV.AA., Libro de actas del XXVI Congreso AGE, Crisis y espacios de oportunidad. Retos para la Geografía (pp 106-120). Valencia: AGE y Universitat de Valencia.

Moscovici, S. (2015). Representações sociais: investigações em Psicologia Social. Petrópolis, RJ: Vozes.

Navia, M. \& Estrada, H. (2012). Uso de la técnica de asociación libre para conocer la percepción del consumidor sobre queso costeño en Colombia. Psicogente, 15 (28), 271-286.

Nogué, J. (1985). Geografía humanista y paisaje. Anales de Geografía de la Universidad Complutense, 5, 93-107.

Onwuegbuzie, A. J., Dickinson, W. B., Leech, N. L. \& Zoran, A. G. (2009). A Qualitative Framework for Collecting and Analyzing Data in Focus Group Research. International Journal of Qualitative Methods, September, 1-21. https://doi. org/10.1177/160940690900800301 
Olcina, J. \& Martín, J. (1999). La influencia del clima en la historia. Madrid: Arco libros.

Olcina, J. (2017). La enseñanza del tiempo atmosférico y del clima en los niveles educativos no universitarios: propuestas didácticas. In R. Sebastiá y E. Tonda, (Dirs.), Enseñanza y aprendizaje de la Geografía para el siglo XXI (pp. 119-148). Alicante: Universidad de Alicante

Ortega, J. (2000). Los horizontes de la Geografía. Teoría de la Geografía. Barcelona: Ariel.

Otzen, T. \& Manterola, C. (2017). Técnicas de Muestreo sobre una Población a Estudio. International Journal of Morphology, 35 (1), 227-232. http://dx.doi.org/10.4067/ $\underline{\text { S0717-95022017000100037 }}$

Pagès, J. (2000). La didáctica de las ciencias sociales en la formación inicial del profesorado. Revista Iber, 24, 33-44.

Sammut, G., Andreouli, E., Gaskell, G., \& Valsiner, J. (2015). Social representations: a revolutionary paradigm? In G. Sammut, E. Andreouli, G. Gaskell \& J. Valsiner, (Eds.), Cambridge Handbook of Social Representations (pp. 3-11). Cambridge: Cambridge University Press.

Saraiva, J. (2007). Habitus docente e representaçao social do "ensinar geografia" na Educaçao Básica de Teresina-Piauí. Programa Posgraduaçao em Educaçao. Natal: Universidade Federal Río Grande do Norte.

Silva, E.A. da \& Viveiros, K.F.M. (2017). Representações sociais de pobreza construídas pelos cursistas da Especialização Educação, Pobreza e Desigualdade Social realizada no Rio Grande do Norte: primeiros resultados. Educar em Revista, 33 (2), 35-54. https://doi.org/10.1590/0104-4060.51389

Soja, E. (2008). Postmetrópolis. Estudios críticos sobre las regiones y las ciudades. Los Ángeles: Traficantes de Sueños.

Souto, X. M. (2013). Didáctica de la Geografía y currículo escolar. In R. De Miguel, M. L. Lázaro \& M. J. Marrón (Coords.), Innovación en la enseñanza de la geografía ante los desafios sociales y territoriales (pp. 121-147). Zaragoza: Ifcz.

Souto, X. M. (2018). La geografía escolar: deseos institucionales y vivencias de aula. Boletín de la Asociación de Geógrafos Españoles, 79, 1-31. https://doi. org/10.21138/bage. 2757

Souto, X. M. \& García-Monteagudo, D. (2019). To know the routines to innovate in school geography. Revista de Geografía Norte Grande, 74, 207-228. https://doi. org/10.4067/S0718-34022019000300207

Stake, R. E. (1999). Investigación con estudio de casos. Madrid: Ediciones Morata. 
Taylor, S. J. \& Bodgan, R. (2000). Introducción a los métodos cualitativos de investigación. $3^{\mathrm{a}}$ ed. Buenos Aires: Paidós.

Tonda, E. \& Sebastiá, R. (2003). Las dificultades en el aprendizaje de los conceptos de tiempo atmosférico y clima: la elaboración e interpretación de climogramas". Revista de Educación de la Universidad de Granada, 16, 47-69.

Travé, G. (Eds.) (2019). La investigación en Didáctica de las Ciencias Sociales. Perspectivas y aportaciones desde la enseñanza y el aprendizaje de las nociones económicas. $1^{\text {a }}$ ed. E-book. Huelva: Publicaciones de la Universidad de Huelva.

Vara, J. L. (2010). Un análisis necesario: epistemología de la geografía de la percepción. Papeles de Geografía, 51-52, 337-344.

Vázquez, B. \& Aguaded, S. (2001). La percepción de los alumnos de Secundaria de la contaminación: comparación entre un ambiente rural y otro urbano. In M. Sánchez \& M. Ortega (Eds.), Reflexiones sobre la Didáctica de las Ciencias Experimentales (pp. 517-525). Madrid: Universidad Complutense de Madrid.

Vigotsky, L. (2010). Pensamiento y lenguaje. Barcelona: Paidós.

Yin, R. K. (1989). Case Study Research: Design and Methods, Applied social research Methods Series. Newbury Park CA: Sage. 